\title{
EL ACTUAL SISTEMA DE PENSIONES COMO MECANISMO REPRODUCTOR DE LA INEQUIDAD DE GÉNERO EN LA VEJEZ
}

\section{THE CURRENT PENSION SYSTEM AS A REPRODUCTIVE MECHANISM OF GENDER INEQUITY IN OLD AGE}

Fecha recepción: 10 de diciembre de 2019 / fecha aceptación: 26 de mayo de 2020

Jacqueline Crespo Amigo ${ }^{1}$

Cómo citar este artículo:

Crespo, J. (2020). El actual sistema de pensiones como mecanismo reproductor de la inequidad de género en la vejez. Revista Pensamiento y Acción Interdisciplinaria, 6(1), 36-70. DOI: http://doi.org/10.29035/pai.6.1.36

\section{Resumen}

Comprender las lógicas que subyacen en el sistema de pensión chileno, y que el lenguaje tecnicista no logra expresar, implica dar una mirada a los factores históricos, socio cultural e idiosincráticos que caracterizaron a Chile, en el período en que se forjo la arquitectura de la previsión social en el país. Implica comprender los tipos de relaciones sociales y de género, en la división sexual del trabajo, que han configurado el tipo de ordenamiento social hegemónico en Chile. De esta forma, el Componente Contributivo o de capitalización Individual es el área de interés en el análisis y crítica a la política del sistema de pensiones en Chile como tema que nos ocupa. Este componente contiene factores de discriminación de género que son regresivos para la condición de la mujer en su etapa de jubilación, tales como una menor tasa de participación laboral femenina; mayores interrupciones laborales de las mujeres en edades reproductivas y/o de crianza y cuidado; segregación laboral vertical y horizontal, entre otros.

Por otra parte, uno de los principales factores del diseño del sistema de pensiones, en su modalidad contributiva o de capitalización individual, que afecta en forma negativa la equidad de género en materia previsional es la exigencia de 240 meses o 20 años de cotizaciones para acceder a una pensión mínima garantizada. En promedio, cuando una mujer se jubila a los 60 años, su ahorro llega a 12,5 millones de pesos, el mismo monto que un cotizante hombre suma a sus 49 años.

Las transformaciones para revertir lo anterior, pasan por la generación de una serie de medidas estructurales en el mercado del trabajo. Se hace necesario un compromiso de parte de todos los actores de la sociedad, donde exista una obligación de realizar una distribución más equitativa de los roles, con visión de largo plazo, voluntad política y sentido de equidad y justicia social.

Palabras clave: cotizaciones, discriminación, mercado laboral, mujer, pensiones, pilar contributivo, vejez

1 Socióloga U. de Chile. Articulo elaborado en el marco de su formación en el Programa de Magister en Políticas Públicas y Procesos Locales Universidad Católica del Maule. Año 2019. Correo electrónico: jcrespoamigo@gmail.com 


\begin{abstract}
Understanding the logics that underlie the Chilean pension system, logics that the technical language cannot express, implies taking a look of the historical, socio-cultural and idiosyncratic factors that characterized Chile in the periods in which the social welfare architecture was forged in the country. It implies understanding the types of social relations and in them, of gender, in the sexual division of labor, and that has configured the type of hegemonic social ordering in Chile.

In this way, the Tax or Individual Capitalization Component is the area of interesting the analysis and criticism of the pension system policy in Chile that concerns us. This component contains gender discrimination factors that are regressive for the status of women in their retirement stage, such as a lower rate of female labor participation; greater work interruptions of women of reproductive and/or Foster age; vertical and horizontal labor segregation, among others.

On the other hand, one of the main factors of the design of the pension system, in its contributory or individual capitalization modality, which negatively affects gender equity in pension matters is the requirement of 240 months or 20 years of contributions for access a guaranteed minimum pension. On average, when a woman retires at age 60, her savings reach 12.5 million pesos, the same amount that a male contributor adds to her 49 years.

The transformations happen, firstly, by the generation of a series of structural measures in the labor market, a commitment is necessary on the part of all the actors of the society, where there is an obligation to make a more equitable distribution of the roles, with a long-term vision, with a political will and a sense of equity and social justice.
\end{abstract}

Keywords; pensions, contributory pollar, contributions, discrimination, labor market, women, old age.

\title{
Sistema de pensiones en Chile; Algunos antecedentes históricos y culturales que explican su orientación patriarcal y sexista
}

El sistema de pensión diseñado y vigente en Chile, a partir del año 1981 fue diseñado, en términos generales, donde la casuística del saber técnico o experto, cumple un rol predominante, expresando una relación de variables que tienen que ver con el funcionamiento del engranaje económico productivo del país, y donde los factores trabajo, empresa, salario y Estado se concatenan en una interrelación insoslayable. Es decir, el sistema de pensión pasa a constituirse en un subproducto de las relaciones entre actores en la actividad económica y por tanto expresan implícitamente un tipo de ordenamiento no solo económico, sino también social y cultural entre actores.

Es por ello que, comprender las lógicas socioculturales que subyacen en los sistemas de pensión, lógicas que el lenguaje tecnicista no logra expresar, implica dar una mirada, aunque sea breve, a los factores históricos, de tipo socio cultural e idiosincráticos que caracterizaron a Chile en los períodos en que se forjo la arquitectura de la previsión social en el país. Implica comprender los tipos de 
relaciones sociales y en ellas, de género, en la división sexual del trabajo, que históricamente se han dado y se dan y que han configurado el tipo de ordenamiento social hegemónico en Chile.

Al respecto, cabe señalar que el tipo de relación social que gesto y gatillo las primeras medidas políticas y legales en favor de proveer algunas seguridades de tipo social en Chile, se dieron al alero de las relaciones de capital y trabajo, en los contextos productivos de una incipiente industrialización o de un capitalismo criollo de comienzos de siglo XX. Escenario donde la presencia eminentemente masculina, en su rol de obrero, artesano o jornalero sin calificación laboral era la "naturalmente" esperada y practicada. Es así como el mundo del trabajo asalariado de comienzos de siglo XX era el mundo del sujeto hombre y este se da en lo público y donde la presencia de la mujer no estaba contemplada bajo ninguna circunstancia. Su presencia en la incipiente política de seguridad social estaba dada como beneficiaria indirecta y no titular, en relación a labores como reproductora, cuidadora y en los espacios de lo privado y como correlato de su relación con el hombre como esposa, hija, viuda, etc.

De esta forma y según lo indicado por González (2017) la división sexual del trabajo en Chile, en tanto normativa sociocultural, ha generado estructuras y patrones en el mercado laboral, en el sentido de reflejar una composición altamente masculinizada en que prima la presencia de hombres. De la misma manera, empleadores y trabajadores, por ejemplo, asumen que el salario de las mujeres trabajadoras es un "segundo salario", dado que el rol principal de los hombres es ser los principales proveedores del núcleo familiar, lo que constituye un factor sociocultural que "justifica" la desigualdad de salarios entre hombres y mujeres.

Dicha situación de supremacía laboral masculina, ha sido un factor sociocultural que ha sido sostenido en el tiempo y que ha sido gravitante en Chile, independientemente de la evolución del modelo de desarrollo y la matriz económica presente en cada etapa de la historia social y económica del país.

El siguiente gráfico muestra una trayectoria de largo alcance respecto del posicionamiento de la mujer en el mercado del trabajo, donde podemos ver que en 25 años la inserción de la mujer en el mercado laboral a ascendido a solo un 15,4 punto porcentual. 
Gráfico 1. Trayectoria participación laboral por género, períodos 1990 - 2015

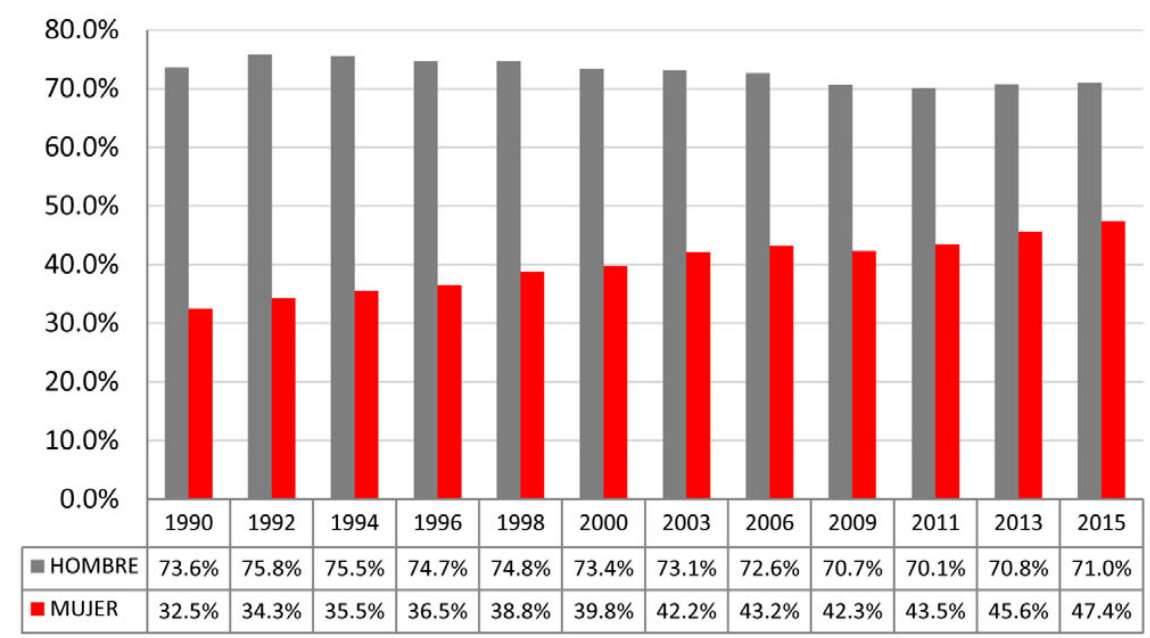

Fuente: La desigualdad previsional de género en Chile, González, 2017.

A su vez, el siguiente gráfico ilustra claramente la poca variabilidad en la evolución de la participación femenina en el mercado laboral, con una muestra más reciente. Durante los años 2014 a 2017. Las cifras indican que, tanto la tasa de participación como de ocupación para la población femenina en los cuatro años señalados ha sido prácticamente nula. Las cifras para hombres han experimentado una muy leve caída para la tasa de participación y una también leve alza para la tasa de ocupación en el periodo indicado. Dicho período considerado no adoleció de variables intervinientes importantes de tipo económicas o políticas que afectaran el escenario para el mercado laboral.

Cuadro 1. Evolución de la tasa de participación laboral femenina en Chile.

Período 2014 a 2017

\begin{tabular}{|l|c|c|c|c|c|c|}
\hline \multicolumn{1}{|c|}{ Año } & \multicolumn{3}{c|}{ Tasa de participación } & \multicolumn{3}{c|}{ Tasa de ocupación } \\
\hline & Total & Hombres & Mujeres & Total & Hombres & Mujeres \\
\hline 2014 & 59.8 & 71.6 & 48.4 & 56.0 & 67.3 & 45.1 \\
\hline 2015 & 59.7 & 71.5 & 48.2 & 56.0 & 67.4 & 44.9 \\
\hline 2016 & 59.5 & 71.3 & 48.0 & 55.6 & 66.9 & 44.7 \\
\hline 2017 & 59.7 & 71.2 & 48.5 & 55.7 & 66.7 & 45.0 \\
\hline Variación [en puntos porcentuales) & -0.1 & -0.1 & -0.2 & 0.0 & 0.1 & -0.1 \\
\hline 2014 - 2015 & -0.2 & -0.2 & -0.2 & -0.4 & -0.5 & -0.2 \\
\hline 2015 - 2016 & -0.2 & -0.1 & 0.5 & 0.1 & -0.2 & 0.4 \\
\hline 2016 - 2017 & 0.2 &
\end{tabular}

Fuente: Organización Internacional del Trabajo (OIT), 2017. 
Por otra parte, cabe señalar la vulnerabilidad sobre la cual descansa el mercado laboral femenino. Al respecto, el siguiente gráfico, con datos muy recientes, incorpora el periodo de del tercer trimestre móvil del año 2019 y el trimestre móvil febrero abril, donde en ambos periodos la curva de la tasa de desocupación subió de manera exponencial, tanto por factores de la contingencia nacional (estallido social) como de la contingencia internacional del COVID 19, donde Chile se ha visto igualmente afectado, cuyos impactos se evidencian no solo en el ámbito sanitario, sino también y con mucha evidencia en el mercado laboral, afectando de manera muy acentuada los puestos laborales de mujeres a nivel nacional, llegando en este caso a casi un $10 \%$ de desempleo a nivel nacional. Lo que permite constatar que la integración femenina en la estructura laboral resulta frágil y se afecta de manera diferenciada con respecto de la integración masculina al mercado laboral.

Gráfico 2. Evolución tasa de desocupación por género país

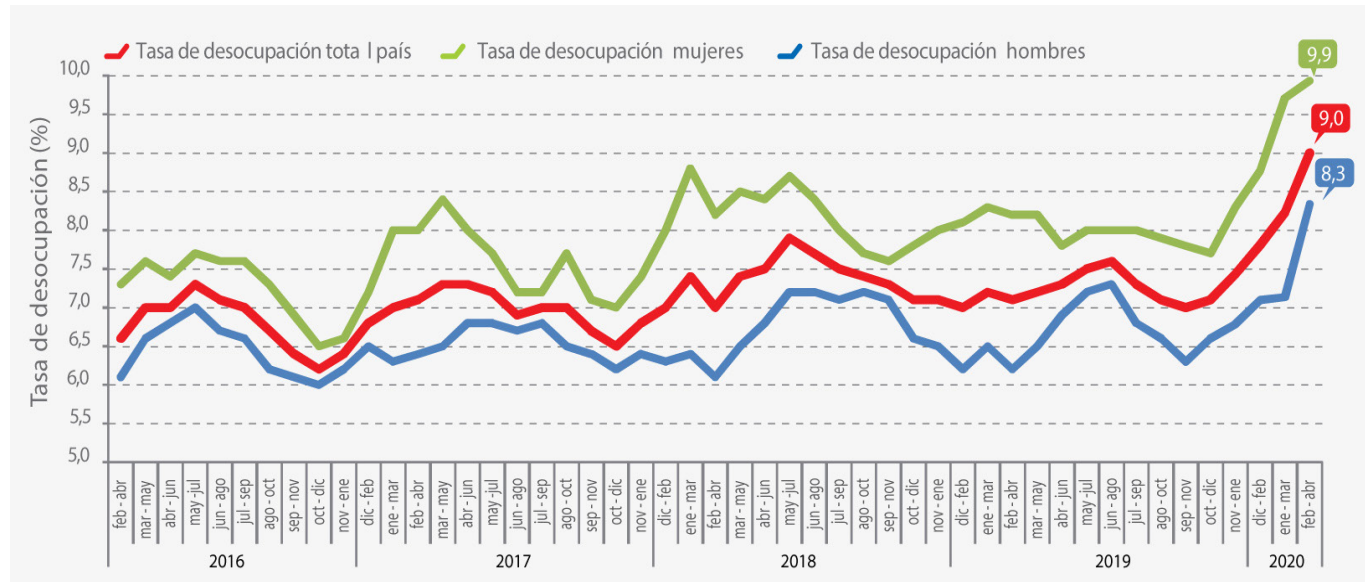

Fuente: Boletín estadístico empleo trimestral 2020, INE, 2020a.

A lo anterior hay que agregar la rezagada inclusión de la mujer al mercado laboral en Chile, en comparación con otras realidades regionales tanto más cercanas como lejanas a la actualidad. Así, 48,9\% al año 2018 según Encuesta Gobierno de Chile (2019), en comparación al promedio de países OCDE correspondiente a un 61,9\% al año 2017. Por debajo del promedio porcentual en América Latina y El Caribe de un 51,7\% (Granados, 2019). Y de otros países de América Latina como Bolivia con un 58\% al año 2019, de su población femenina integrada al mercado laboral. (Banco Mundial, 2019).

Al respecto y según González (2017), en la base de esta inactividad está la cultura machista, con una fuerte división sexual del trabajo, donde mayoritariamente los hombres son proveedores y las mujeres cuidadoras. Una de sus 
expresiones es el embarazo adolescente o la maternidad como único proyecto de realización personal de algunas mujeres, lo que disminuye las posibilidades de que las jóvenes continúen educándose, exponiéndolas a trabajos informales, mal remunerados y/o a no tener acceso a la fuerza laboral. Ello perpetúa el ciclo vicioso de la pobreza, tanto en su vida activa como en el retiro.

Situación desmedrada que como ya se verá, afecta toda la cadena productiva de la mujer en su rol activo de capitalizadora para su futura pensión. Es decir, la configuración socio cultural de la división sexual del trabajo y sus cosmovisiones afectan tanto la inserción de la mujer al mundo del trabajo y, por ende, también afecta la concepción, definición, operatoria y modelo de intervención del sistema previsional, traduciéndose en un círculo vicioso que reproduce en ambas esferas la discriminación hacia la mujer, tanto en su tiempo laboral activo, como y de manera consecuente, en su tiempo de retiro laboral.

Asimismo, cabe agregar lo señalado por la CEPAL (2002), donde indica que.

La mayoría de los regímenes de seguridad social se establecieron sobre la base del modelo patriarcal en el que los hombres eran considerados el sostén de la familia. En ese contexto la edad de jubilación era considerada inferior para las mujeres en el entendido que la participación de la mujer era complementaria a la del hombre, en tal sentido las mujeres se encontraban a menudo en una posición de desventaja en el trabajo, determinada por la división del trabajo. (p. 23).

El mercado laboral chileno, como ya se pudo observar, no ha quedado al margen de esta realidad, donde la discriminación contra la mujer se traduce en menores remuneraciones y, en el plano previsional, en cotizaciones más bajas o en falta de previsión para las mujeres que se dedican a labores hogareñas, entendidas estas como labores de cuidado del hogar, crianza, cuidado y atención de personas con dependencia física, debiendo ser solo acreedoras del Pilar Solidario con una pensión básica otorgada por el Estado. Esto ha producido que el empleo femenino se distribuya desigualmente según el nivel socioeconómico, lo que produce un círculo vicioso de pobreza femenina, donde a menos empleo, mayor pobreza y mayor precariedad. (Maldonado \& Palma, 2013).

Actualmente, sin considerar las inactivas por razones de estudios, problemas de salud permanente, jubilación o pensión y, según el INE (2016) el 74,3\% de las mujeres que está fuera de la fuerza laboral lo hace por "razones familiares permanentes"2. Es decir, 1.364.000 mil mujeres no están acumulando recursos en sus cuentas individuales de previsión social².

2 INE. Menos del 50\% de las Mujeres Participó en la Fuerza Laboral Durante el 2015 en línea http://www.ine.cl/prensa/ detalle-prensa/2016/05/30/menos-del-50-de-las-mujeres-particip\%C3\%B3-en-la-fuerza-laboral-durante-2015 Revisado el 9 de mayo de 2019.

3 Ibidem. 


\section{Sistema de pensiones en Chile. El Componente Contributivo y sus elementos de discriminación de género.}

El actual sistema de pensiones en Chile está conformado por tres componentes o también llamados Pilares"; Por una parte, está el Pilar Solidario o No Contributivo, también Ilamado Pensión Básica Solidaria que se otorga a la población que nunca cotizo en el sistema de AFP, cuyo monto alcanza actualmente los \$ 107.000 mensuales. Es otorgado por el Estado vía impuestos generales (IVA). El Pilar Solidario también está compuesto por el Aporte Previsional Solidario (APS) que es un aporte monetario financiado por el Estado para mejorar las pensiones de las personas que, habiendo cotizado, obtienen una pensión muy baja. Se calcula dependiendo del monto de la pensión autofinanciada y no superará la Pensión Máxima con Aporte Solidario. (CEPAL 2010). Este aporte solidario también es financiado por impuestos generales.

El otro componente del sistema previsional chileno es el Componente Contributivo, o también Ilamado de Capitalización Individual, cuya administración es vía AFP. (Fundación SOL, 2014). En dicho componente participan los y las trabajadoras que están insertos en el mercado laboral, que han tenido relación laboral con algún empleador de manera formal, es decir, vía contrato laboral y que han percibido alguna remuneración. También lo integran aquellas mujeres que, desempeñando una actividad laboral independiente o por cuenta propia, son ellas mismas quienes hacen su aporte mensual en sus cuentas individuales. Este componente se caracteriza en que la densidad de cotizaciones (número de cotizaciones), alcanzada al final de la vida laboral del o la trabajadora dependerá directamente de la regularidad y estabilidad en su trayectoria laboral, es decir en la estabilidad de sus ingresos. Asimismo, el monto de la pensión y según la teoría que sustenta el sistema, está íntimamente ligado tanto a la densidad de cotización como al monto de esta misma. Lo que implica una relación directa con el monto del salario percibido. Por lo tanto, el principio que rige este sistema es el de la responsabilidad individual en alcanzar la suficiencia (concepto que se le otorga a la capacidad de la pensión para solventar los gastos derivados de las necesidades de mantención en la etapa de jubilación), de la pensión recibida al momento de jubilar. Es decir, se sustenta en un enfoque individualista de la responsabilidad del éxito o fracaso en el monto de la pensión alcanzada.

De esta forma, el Componente Contributivo o de capitalización Individual es el área de interés en el análisis y critica a la política del sistema de pensiones en Chile. Al respecto, los estudios realizados por Arenas de Mesa y Gana Cornejo (2003; 2001) señalan dos factores que afectan negativamente la pensión de las

\footnotetext{
4 Para la ocasión dejaremos al margen el sistema de pensiones para las Fuerzas Armadas y de orden que, pese a ser estatal y de reparto, su particular mecanismo de funcionamiento no representa ni cubre una porción significativa de población tanto general como femenina, pese a resultar muy oneroso para el Estado. Asimismo, no se considerará para esta ocasión el Aporte Previsional Voluntario APV. Por ser un mecanismo de mejoramiento de los montos de cotización marginal, ya que la población que accede a este tipo de aporte es un número reducido de población, cuyos mecanismos de funcionamiento resultan muy particulares.
} 
mujeres en el componente contributivo y que operan como dispositivos o superestructuras económicas de discriminación de género y que son regresivos para la condición de la mujer en su etapa de jubilación, siendo; a) factores del mercado laboral y b) factores del diseño del sistema de pensiones.

\section{Factores del mercado laboral}

1.- menor tasa de participación laboral femenina; Corresponde al porcentaje de población femenina en edad productiva, inserta efectivamente en el mercado laboral sea formal o informal, es decir, la población femenina que desarrolla una labor de la cual percibe una remuneración.

2.- mayores interrupciones laborales de las mujeres en edades reproductivas y/o de crianza; condición que se refleja por la acentuada división sexual del trabajo tanto productivo como reproductivo, donde las interrupciones laborales dadas por períodos de crianza son asumidas en gran proporción por mujeres. Solo como una aproximación a esta realidad, Barriga et, al (2020) señalan que, en el marco del ciclo de vida familiar, en el Inicio Ciclo Familia, es decir, en el período de crianza, las mujeres realizan cerca de 70 horas semanales de trabajo no remunerado al interior del hogar, en comparación a 31 horas promedio que realizan los hombres. Cabe agregar que, en ello, la legislación chilena está en muy desventaja como instrumento que permita una distribución equitativa en las labores de cuidado y crianza de los hijos, en comparación a otros países de la OCDE. Siendo, por una parte, un instrumento que otorga poco margen de tiempo inexcusable al hombre en el cuidado y crianza de los hijos y quedando a discreción de la madre el compartir equitativamente su período de licencia post natal. Siendo esta normativa uno de los pocos avances valorados socialmente en la materia en los últimos años.

3.- segregación laboral vertical y horizontal de las mujeres en sectores y ocupaciones de menores remuneraciones; lo que equivale a que, y siguiendo el patrón cultural de división sexual del trabajo y de devaluación del trabajo culturalmente asignado a las mujeres, la segregación horizontal se expresa en una mayor concentración de mujeres en trabajos remunerados que tienen que ver tanto con servicios, sean de cuidado o formación de otro, como con servicios que incorporan poca calificación o son homologables a labores domésticas, como por ejemplo labores de limpieza y/o manipulación de alimentos remunerado y/o fuera del hogar. Por su parte la segregación vertical tiene que ver con la participación de la mujer en la pirámide del mercado laboral en razón de su calificación, escolaridad, nivel de jerarquía respecto de cadena de 
mando y responsabilidad de las funciones. En este aspecto, nuevamente Barriga et, al (2020) proporcionan datos que orientan y contextualizan una realidad; de la distribución porcentual según categoría de ocupación y sexo un $97,6 \%$ de población que trabaja en servicios domésticos son mujeres contra tan solo un 2,4\% desarrollado por población masculina. Así también, un 73,6\% de la población que se agrupa como empleador corresponde a hombres, donde solo un $26,4 \%$ corresponde a mujeres. Así también un 69,3\% de la población que se agrupa en la categoría de directores, gerentes y administradores corresponde a población masculina, y solo un 30,7\% corresponde a población femenina. Pese a la tendencia progresiva de aumento en la escolaridad de las mujeres en los últimos veinte años.

4.- mayor proporción de mujeres en trabajos de jornada parcial, temporales e informales; fenómenos que agrupados y en conjunto grafican una condición estructural del mercado del trabajo y cultural; de las subjetividades, construcciones de roles sociales y valoraciones subyacentes a ello que indican de una persistente segregación laboral femenina, que no brinda las condiciones para que las trayectorias laborales femeninas sean más consistentes y estables en el tiempo. Cabe agregar al respecto y, pese a las transformaciones socioculturales, que expresan por ejemplo la configuración de la familia nuclear o tradicional, donde la figura de la familia biparental, heterosexual, con hijos donde el único o principal proveedor es la figura masculina hombre - padre de familia, pierde cada vez más hegemonía como categoría social. Dados los altos índices de familias cuya composición escapa a la configuración tradicional biparental con hijos, donde las familias extendidas, de filiación no sanguínea y monoparentales, especialmente con jefatura de hogar femenina aumentan exponencialmente. Pese a ello, persisten estructuras laborales y normativas, así como disposiciones valorativas y culturales de discriminación laboral femenina, chocando con una realidad que indica que la presencia femenina en los espacios laborales se hace una necesidad y realidad social y económica cada vez más urgente, devaluando, con ello, además, la riqueza y complejidad del valor creativo y productivo que la mujer puede aportar en el desarrollo de una sociedad más justa y equitativa.

5.- mayores tasas de desempleo entre mujeres. En Chile el año 2019 alcanzo un porcentaje de un 7,7\% según estimaciones del Banco Mundial (2019a).

6.- discriminación salarial. Según el INE (2018), en su Encuesta Suplementaria de Ingresos ESI del mismo año, las mujeres ganan un 27, $2 \%$ menos de ingreso que los hombres. Así, el promedio de ingresos percibido por estas fue de $\$ 474.911$ mensuales en relación a los $\$ 652.397$ percibidos como promedio mensual por los hombres. 
Los factores anteriormente mencionados generan menores ingresos laborales para las mujeres y, por ende, menores cotizaciones, menor acumulación de fondos previsionales y, por lo tanto, menores pensiones de vejez en relación con los hombres.

De esta forma, las mujeres, a quienes el orden de relaciones de género existente atribuye la mayor parte del trabajo doméstico y de cuidado familiar, tienen mayores dificultades que los hombres para insertarse al mercado laboral y desarrollar trayectorias laborales que garanticen ahorros previsionales y derechos a prestaciones suficientes.

En efecto, en Chile, al trimestre móvil octubre-diciembre del año 2019 la tasa de participación femenina en el mercado laboral fue de un 49,2\% en relación a la tasa de participación masculina en igual período, de un 69,7\% según el Instituto Nacional de Estadísticas INE (2020b).

Si bien se ha elevado la participación de las mujeres en el trabajo remunerado, ésta sigue siendo más inestable e intermitente que la de los hombres. La desventajosa manera en que grandes grupos de mujeres se insertan en el mercado laboral y las dificultades que enfrentan en sus trayectorias laborales vulneran notoriamente sus derechos a prestaciones previsionales. Estas registran una tasa de desempleo más alta y se retiran del mercado laboral más a menudo y por un tiempo más prolongado que los hombres, dado por obligaciones de cuidado y crianza.

El grado de inserción laboral y sus características son condicionantes importantes de la participación de las mujeres en el sistema de pensiones. Al respecto, según el INE (2018) para ese año el 40,1\% de las mujeres de 15 años y más que no estudiaban no tuvo ingresos propios, ni por actividades remuneradas en el mercado laboral, ni por rentas a la propiedad, seguro de cesantía o jubilaciones. Es decir, dicho porcentaje de mujeres no cuenta con autonomía económica. Por su parte, la población masculina con mismas características tan solo un 15\% no logro percibir ingresos propios.

Lo anterior se refleja y redunda, en primer lugar, en una baja proporción de mujeres, en relación a los hombres, afiliadas al sistema de pensiones, situación señalada por la Super Intendencia de Pensiones de menara precisa en el siguiente gráfico: 
Gráfico 3. Proporción (\%) de mujeres respecto del total de afiliados/cotizantes del Seguro de Cesantía

Junio 2018
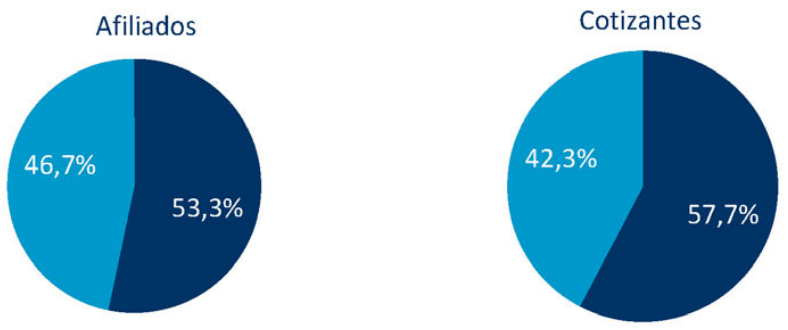

- Afiliados hombres

Afiliadas mujeres

- Cotizantes hombres Cotizantes mujeres

Fuente: Informe de género sobre el sistema de pensiones y el seguro de cesantía, Superintendencia de Pensiones, 2018.

Tanto el porcentaje de afiliados y cotizantes reflejan brechas notorias en desmedro de las mujeres trabajadoras. Más aun preocupante, es la brecha que existe entre cotizantes hombres y mujeres, es decir, quienes efectivamente aportan mensualmente a sus cuentas individuales la que alcanza cerca de los 16 puntos porcentuales, reflejando con ello, las condiciones de flexibilidad, precariedad e inestabilidad laboral que presentan las trayectorias laborales femeninas.

En segundo lugar, en una menor densidad ${ }^{5}$ de las cotizaciones de las afiliadas en comparación con los hombres que tienen una mayor cantidad de afiliados con una mayor densidad de cotizaciones. Al respecto y según datos de la Superintendencia de Pensiones (2019) los hombres registraron a junio del año 2018 una densidad promedio de cotización desde su afiliación al sistema de pensiones de 58,1\%, En el caso de las mujeres alcanzó el 47,7\%. Un diez por ciento porcentual menos.

\section{Factores del diseño del sistema de pensiones}

En relación a las inequidades de género determinadas por el diseño del sistema de pensiones, se ha constatado que éstas se potenciaron con las reformas estructurales del sistema de pensiones chileno impuestas a principios de la década de los ochenta.

5 Densidad de cotizaciones corresponde al cociente entre la cantidad de cotizaciones efectivas que registra el trabajador en la cuenta individual con respecto a la cantidad de cotizaciones que registraría si se diera el caso ideal de que el trabajador cotizara durante todos y cada uno de los meses durante su vida activa. 
El transito del principio de un seguro social Solidario, que establece transferencias entre generaciones (jóvenes/viejos), de Reparto entre grupos de ingresos (ingresos bajos/ingresos altos) y entre géneros (hombres/mujeres) a la individualización de los riesgos de la vejez fue acompañado por la intensificación del carácter contributivo del sistema de pensiones. Esto significa que se establecieron condiciones de adquisición de derechos previsionales más estrictos, por ejemplo, más años de contribución para acceder a las prestaciones o garantías públicas.

Todo esto hizo que las mujeres asumieran en forma mucho más directa que en el antiguo sistema público de reparto las desventajas que enfrentan en el mercado laboral. Así, las brechas salariales entre hombres y mujeres existentes en el mercado laboral se ampliaron y se hicieron más evidentes al pasar desde un sistema de pensiones, solidario y tripartito (aportan tanto trabajador, empleador y Estado) a uno de capitalización individual. Hecho que se evidencia al comparar las tasas de reemplazo de hombres y mujeres.

1) Tasa de reemplazo; Definida como el monto de la pensión recibida en relación al monto del último salario o del promedio del salario en los últimos diez años de actividad laboral. El sistema en sus orígenes aseguraba una tasa de reemplazo del $70 \%$ del monto de la pensión en relación al último salario percibido. Lo anterior si se reunían una serie de factores o variables de tipo económicas como una estabilidad laboral sostenida en la totalidad de trayectoria laboral de la trabajadora y un incremento del salario sostenido. Elementos que no fueron sostenibles dados por factores económicos intervinientes, tales como la crisis económica y social de 1982-1983, la creciente devaluación de los salarios y una caída del PIB, que no permitió cumplir dicha tasa de reemplazo, siendo una constante sostenida en el tiempo desde los registros estadísticos de los primeros grupos de trabajadores jubilados con el actual sistema. En cifras actuales y según el siguiente cuadro, el promedio de la tasa de reemplazo período 2007-2017 es de un 56\% para los hombres y un 31\% para las mujeres, es decir, en este período los hombres han percibido como monto promedio de pensión el equivalente al $56 \%$ de su último salario antes de retiro. Asimismo, las mujeres han percibido como monto de pensión promedio el 38\% de su último salario antes de pasar a retiro, lo que evidencia una brecha previsional de género sostenida en el tiempo. (Superintendencia de Pensiones, 2018). 
Cuadro 2. Tasa de reemplazo por sexo

Tasa de reemplazo efectiva pensionados 2007 y 2017

(TR mediana del último ingreso)

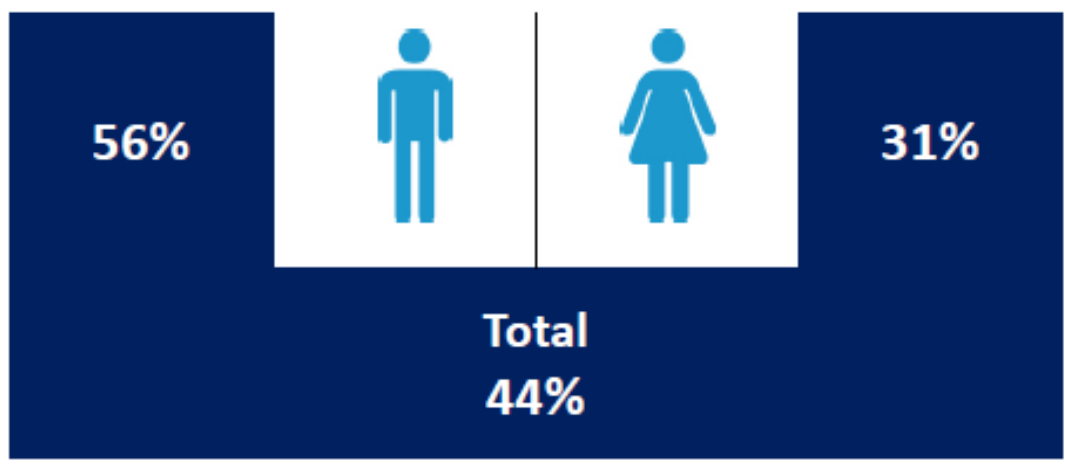

Fuente: Informe de género sobre el sistema de pensiones y seguro de cesantía, Superintendencia de pensiones, septiembre 2018a.

Al respecto cabe la siguiente interrogante ¿Qué factores definen la acentuada brecha en la tasa de reemplazo entre género? Es posible determinar que este factor técnico es el resultado final de un mercado laboral diseñado estructuralmente con rasgos de inequidad de género, tanto de acceso al mundo laboral, donde en las variables de valoración cultural de expertise y calificación laborales la supremacía masculina es determinante, donde igualmente por aspectos culturales de nuestra sociedad la estructura de salarios es desigual en desmedro del trabajo femenino, independiente de la actividad laboral y escolaridad que presentes hombres y mujeres y donde sigue teniendo preeminencia una distribución desigual en el tempo dedicado al cuidado de los hijos y de la atención del hogar, labores que no tienen retribución económica ni están reconocidos por la institucionalidad del trabajo como labores que aportan a la cadena productiva y a la reproducción social, bajos salarios percibidos en general por el trabajo femenino, trayectorias laborales más inestables, precarias e irregulares por parte de la mujer trabajadora, por labores de cuidado y crianza. Cumulo de variables que adquieren sentido en la práctica a partir de una normativa que alienta y constriñe las relaciones de género y el estatus de la mujer en la estructura laboral y productiva. lo que, sumado a factores de diseño del modelo de pensiones, tales como una edad de retiro laboral desigual entre géneros, un sistema de ahorro personal, donde solo el trabajador aporta vía cotizaciones a su cuenta individual y donde las tablas de mortalidad aplicadas al sistema son de mayor expectativa de vida para las mujeres. Todos aspectos que determinan y condicionan que las mujeres alcancen una más baja tasa de reemplazo, respecto de su último salario al momento de jubilar. 
2) Densidad de cotizaciones: Por otra parte, uno de los principales factores del diseño del sistema de pensiones, en su modalidad contributiva o de capitalización individual, y que afecta en forma negativa la equidad de género en materia previsional es la exigencia de 240 meses o 20 años de cotizaciones para acceder a una pensión mínima garantizada cien por ciento con ahorros previsionales. Esto perjudica en mayor grado a las mujeres, a quienes resulta más difícil cumplir con 20 años de aportes al sistema provisional.

Así, el gráfico 2 y según la Superintendencia de Pensiones, a junio de 2018 la mayor concentración de cotizantes femeninas se concentra en el tramo de ahorro previsional de 0 a un año, concentrando sobre las 800 mil cotizantes, la curva desciende en la medida que aumentan los años de cotización, para subir levemente a cerca de 500 mil cotizantes en el tramo de 9 a 10 años cotizados, para finalmente disminuir ostensiblemente el número de cotizantes al llegar al tramo de diez años de ahorro previsional. Por su parte, la curva que grafica la trayectoria de cotizaciones para la población masculina presenta un desarrollo inverso, ya que, a mayor años de ahorro previsional, aumenta el número de cotizantes hombres, evidenciado una mayor consistencia en su trayectoria de ahorro previsional, pese a que, al igual que las mujeres, ellos presentan un notorio decrecimiento de su participación al llegar al tramo de diez años de ahorro previsional, siempre superior al indicado por las mujeres en este tramo.

Gráfico 4. Sistema de Capitalización Individual

Número de afiliados según tramos de densidad de cotizaciones. Junio 2018

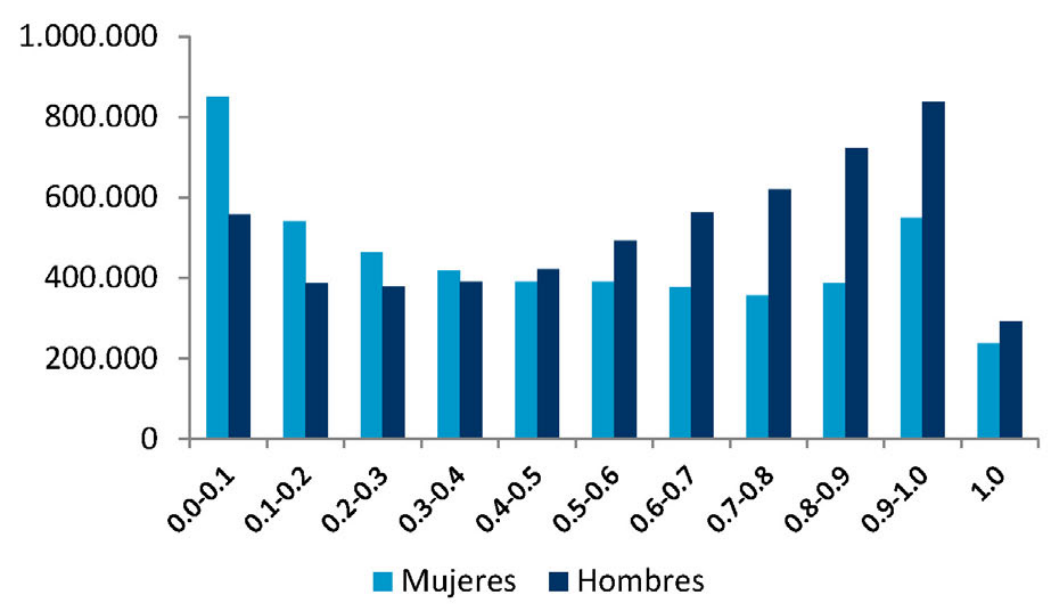

Fuente: Informe de género sobre el sistema de pensiones y seguro de cesantía, Superintendencia de pensiones, septiembre 2018a. 
Asimismo, el siguiente cuadro evidencia el monto de las pensiones percibidas por las mujeres según años de cotización donde cerca del 60\% de la población femenina se concentra hasta el tramo de 15 a 20 años de cotización efectiva. Así, más del $60 \%$ de esta población no alcanza a percibir $\$ 200.000$ al mes de pensión.

Cuadro 3. Pensiones de vejez mujeres, según años de cotización, diciembre 2019

\begin{tabular}{|c|c|c|c|c|c|c|}
\hline $\begin{array}{c}\text { Tramos } \\
\text { AÑos Cotizados }\end{array}$ & Número & $\%$ DEL Total & $\begin{array}{l}\text { Pensión A } \\
\text { Promedio }\end{array}$ & $\begin{array}{l}\text { OFINANCIADA } \\
\text { MEDIANA }\end{array}$ & $\begin{array}{r}\text { Pensió } \\
\text { Promedio }\end{array}$ & $\begin{array}{l}\text { Total } \\
\text { MEDiAnA }\end{array}$ \\
\hline$>0 \mathrm{y}<=1$ año & 25.129 & $5,3 \%$ & $\$ 71.341$ & $\$ 29.442$ & $\$ 149.760$ & $\$ 138.719$ \\
\hline$>1 \mathrm{y}<=5$ & 52.869 & $11,2 \%$ & $\$ 102.199$ & $\$ 137.586$ & $\$ 152.024$ & $\$ 137.869$ \\
\hline$>5 \mathrm{y}<=10$ & 63.832 & $13,5 \%$ & $\$ 125.130$ & $\$ 137.869$ & $\$ 159.102$ & $\$ 137.869$ \\
\hline$>10 y<=15$ & 67.786 & $14,4 \%$ & $\$ 146.362$ & $\$ 137.869$ & $\$ 176.088$ & $\$ 137.869$ \\
\hline$>15$ y $<=20$ & 67.898 & $14,4 \%$ & $\$ 178.353$ & $\$ 137.869$ & $\$ 204.681$ & $\$ 155.705$ \\
\hline$>20 y<=25$ & 68.707 & $14,5 \%$ & $\$ 212.608$ & $\$ 142.399$ & $\$ 232.708$ & $\$ 166.179$ \\
\hline$>25$ y $<=30$ & 57.197 & $12,1 \%$ & $\$ 273.474$ & $\$ 211.192$ & $\$ 289.894$ & $\$ 242.899$ \\
\hline$>30 y<=35$ & 39.933 & $8,5 \%$ & $\$ 340.285$ & $\$ 277.721$ & $\$ 348.495$ & $\$ 287.629$ \\
\hline$>35 \mathrm{y}<=40$ & 10.890 & $2,3 \%$ & $\$ 486.648$ & $\$ 395.490$ & $\$ 488.630$ & $\$ 395.773$ \\
\hline $\mathrm{S} / \mathrm{I}$ & 18.102 & $3,8 \%$ & $\$ 90.875$ & $\$ 103.331$ & $\$ 130.509$ & $\$ 129.093$ \\
\hline Total & 472.343 & $100,0 \%$ & $\$ 186.279$ & $\$ 137.869$ & $\$ 216.005$ & $\$ 149.193$ \\
\hline
\end{tabular}

Fuente: Galvéz \& Kremerman, 2020.

3) Tablas de mortalidad; Otro de los factores discriminatorios del diseño del sistema de pensiones ha sido la aplicación de las conocidas tablas de expectativa de vida diferenciadas por sexo que castigan la mayor esperanza de vida de las mujeres en comparación con los hombres.

El siguiente cuadro expresa la composición y características demográficas actuales en el país el cual indica un aumento de la población de 64 años y más superando los dos millones de personas y una alta presencia de población femenina en este grupo etario. 
Cuadro 4. Composición de la población en Chile al año 2017

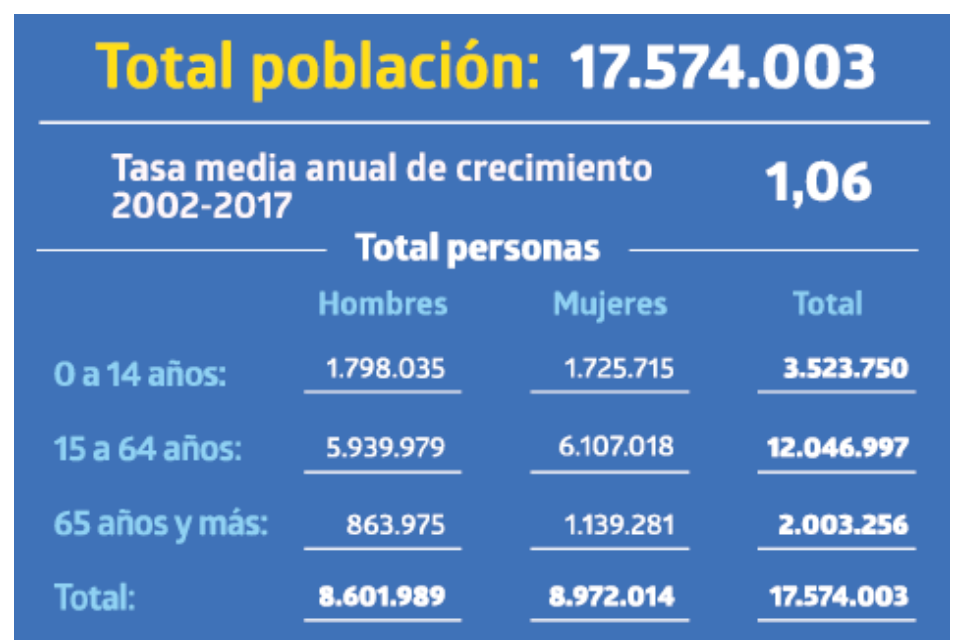

Fuente: Resultados definitivos en base a censo 2017, INE, 2018.

Es así como la tendencia demográfica señalada, significa que la suma acumulada en la cuenta individual de la mujer al momento de jubilar se divide por un promedio de esperanza de vida mayor, por lo cual las pensiones de las mujeres son menores que las de los hombres, aunque ellas tengan los mismos montos acumulados en sus cuentas individuales. Este efecto negativo se potencia con la menor edad legal de retiro de las mujeres (60 años vs. 65 años para los hombres) lo que significa menos años para acumular fondos en sus cuentas individuales. La lógica del funcionamiento de este factor de discriminación se explica en que en un escenario ideal o desde la teoría del sistema, se considera un individuo que comienza a cotizar a los 20 años y se pensiona a los 60 años, en comparación con un escenario que grafica más fehacientemente lo que ocurre en la práctica donde un individuo empieza a cotizar a los 30 años o muy cercano a dicha edad y se jubila a los 60 años. A ello se agrega una trayectoria laboral femenina muy caracterizada por constantes episodios de paros o lagunas laborales, con una periodicidad de cotizaciones discontinuos, sumado a un bajo salario en términos reales. Finalmente, el sistema supone (en la teoría) el cálculo de una rentabilidad del $5 \%$ del fondo.

Lo descrito se grafica como saldo final en las cuentas individuales al momento de jubilar de parte de la población femenina, donde las brechas de los montos ahorrados, en comparación con lo ahorrado por la población masculina y en todos los tramos de ahorro resultan en clara desventaja hacia las mujeres:

El siguiente cuadro ilustra los montos y las condiciones financieras con que se enfrentan el tramo de la población femenina en edad de jubilar o pronta a jubilar. Así, el mayor número de afiliadas 271.664, el 61,7\% de esta población se 
concentra con un saldo hasta diez millones de pesos. En contraste, solo 24.930 afiliadas prontas a jubilar suman a su saldo de cuenta individual entre cincuenta y ochenta millones de pesos. Lo que refleja una clara precariedad en su futura vida como jubiladas, sumado a unas tablas de mortalidad que claramente exceden la esperanza de vida, calculada para esta población según criterios sanitarios y demográficos.

Cuadro 5. Saldo en la cuenta individual de las mujeres afiliadas al sistema de AFP que se encuentran cerca de cumplir su edad legal de jubilación (dic. 2019)

\begin{tabular}{ccc}
\hline \multirow{2}{*}{ Saldo Cuenta Individual } & \multicolumn{2}{c}{ Mayores de 55 hasta $\mathbf{6 0}$ años } \\
\cline { 2 - 3 } & $\mathbf{N}^{\circ}$ de Afiliadas & \% de Afiliadas \\
\hline Hasta $\$ 10$ millones & 271.664 & $61,7 \%$ \\
Más de $\$ 10$ millones hasta $\$ 20$ millones & 63.462 & $14,4 \%$ \\
Más de $\$ 20$ millones hasta $\$ 30$ millones & 27.981 & $6,4 \%$ \\
Más de $\$ 30$ millones hasta $\$ 50$ millones & 31.605 & $7,2 \%$ \\
Más de $\$ 50$ millones hasta $\$ 80$ millones & 24.930 & $5,7 \%$ \\
Más de $\$ 80$ millones hasta $\$ 100$ millones & 9.149 & $2,1 \%$ \\
Más de $\$ 100$ millones & 11.498 & $2,6 \%$ \\
\hline Total & $\mathbf{4 4 0 . 2 8 9}$ & $\mathbf{1 0 0 , 0 \%}$
\end{tabular}

Fuente: Barriga, F., Duran G., Sáez, B., \& Sato, A., 2020.

De esta manera, al tener menos dinero acumulado en sus cuentas individuales y tener que cubrir un período de tiempo de vida pasiva más prolongado, las pensiones a las que las mujeres pueden acceder son más bajas que las de los hombres. Traduciéndose en un camino que inexorablemente conduce a la mayor precarización social y pobreza económica para la mujer en la vejez. 


\section{El impacto combinado de los factores mercado laboral y diseño del sistema previsional-cobertura, beneficios, gasto fiscal.}

Antes de entrar de lleno al análisis del impacto combinado de los factores de diseño del sistema de pensiones y del mercado laboral chileno, es ilustrativo dar una breve mirada a la condición de la mujer de los países de la OCDE al cual pertenece Chile, respecto de su situación al momento de jubilar, teniendo como referencia las variables técnicas que intervienen al momento del retiro, que en términos generales son similares: Porcentaje de cotización (que define, en parte el monto del saldo de ahorro al momento del retiro), edad de jubilación y el tiempo mínimo activa dentro del sistema, para acceder a una pensión completa y el tiempo mínimo para acceder a una pensión parcial. Las anteriores son variables transversales a todos los sistemas de pensiones que actualmente existen para el componente contributivo; de reparto en su totalidad; sistemas mixtos, donde hay un porcentaje de reparto y otro de capitalización individual y de capitalización individual de administración privada absoluto, como es el caso único de Chile. En el siguiente recuadro se observa cuáles son las ponderaciones y valores para cada una de las variables ya mencionadas.

Cuadro 6. Edad de retiro, tasa de cotización y requisitos de cotizaciones por país OCDE año 2017

\begin{tabular}{|c|c|c|c|c|c|c|}
\hline \multirow[b]{2}{*}{ País } & \multicolumn{3}{|c|}{ Cotizaciones } & \multicolumn{3}{|c|}{ Requisitos para acceder a pensión } \\
\hline & Total & Trabajador & Empleador & Edad de retiro & $\begin{array}{c}\text { Tiempo mínimo } \\
\text { pensión completa }\end{array}$ & $\begin{array}{l}\text { Tiempo mínimo } \\
\text { pensión parcial }\end{array}$ \\
\hline Australia & $9,50 \%$ & $0 \%$ & $9,50 \%$ & 57 & $\mathrm{n} / \mathrm{a}$ & $\mathrm{n} / \mathrm{a}$ \\
\hline Chile & $10 \%$ & $10 \%$ & $0 \%$ & 60 & $\mathrm{n} / \mathrm{a}$ & $\mathrm{n} / \mathrm{a}$ \\
\hline Dinamarca* & 94,95 a 284 coronas & $1 / 3$ & $2 / 3$ & 65 & 49 & $\mathrm{n} / \mathrm{a}$ \\
\hline Japón* & 16340 yenes y $18,3 \% * *$ & 16340 yenes y $9,15 \%$ & $9,15 \%$ & 65 (NP) 61 (EPI) & 40 & 10 \\
\hline Noruega & $29,40 \%$ & $13,30 \%$ & $16 \%$ & 67 & 40 & 3 \\
\hline Países Bajos & $17,90 \%$ & $17,90 \%$ & $0 \%$ & 66 & 50 & prop \\
\hline Suiza & $15,40 \%$ & $7,70 \%$ & $7,7 \% * * *$ & 64 & 44 & 1 \\
\hline UK & $25,80 \%$ & $12 \%$ & $13,80 \%$ & 66 & 35 & 10 \\
\hline
\end{tabular}

n/a: No aplica

* En Dinamarca la suma fija sería equivalente a una tasa de cotización del 1,0\%. En Japón la suma fija sería equivalente a una tasa de cotización del 11,6\% (total de 29,9\%).

** Gobierno subsidia en $50 \%$ en costo del sistema de pensiones nacional, destino de la cotización fija.

*** Mínimo, cotizaciones pueden llegar al 26,4 \% (13,2\% cada parte) según la edad.

**** Elemento contributivo originalmente 62, con 12000 días de aportes (32 años).

***** Promedio de 48 semanas anuales de cotizaciones desde ingreso al mercado laboral anterior a los 56 años.

Fuente: Social Security Admistration (2018), "Social Security Programs Throughout the World". Superintendencia de pensiones.

Fuente: CIEDESS, 2019. 
El cuadro anterior muestra que solo en Chile y los Países Bajos el empleador no participa de las cotizaciones de la mujer trabajadora. Respecto de la edad de jubilación Chile es el único país que asigna los sesenta años para el retiro laboral de la mujer y respecto del tiempo mínimo exigido para acceder a una pensión completa, Chile y Australia no establecen un criterio definido dentro de sus sistemas de pensiones para acceder a una pensión completa.

Asimismo, y de acuerdo a la simulación técnica elaborada por CIEDESS (2019) se observa cual sería la situación de la población femenina, al momento de jubilar cumpliendo los requisitos técnicos antes mencionados y de acuerdo a lo ponderado en ello para cada país:

Cuadro 7. Parámetros de jubilación y pensiones estimadas por país OCDE año 2017

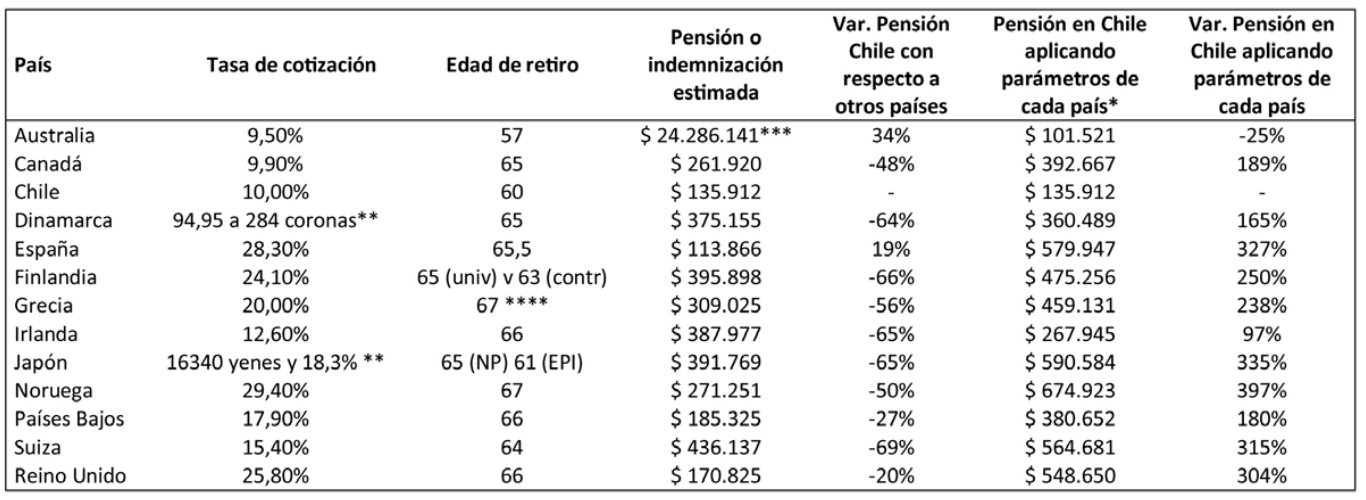

* Pensión estimada en Chile utilizando los parámetros de cada país (tasa de cotización y edad de retiro).

** En Dinamarca la suma fija sería equivalente a una tasa de cotización del 1,0\%. En Japón la suma fija sería equivalente a una tasa de cotización del 11,6\% (total de 29,9\%).

*** Pago suma alzada. Equivalente a una pensión de \$101.521.

**** Elemento contributivo originalmente 62, con 12000 días de aportes (32 años).

Fuente: Social Security Admistration (2018), "Social Security Programs Throughout the World". Superintendencia de pensiones.

Fuente: CIEDESS ,2019.

El cuadro anterior señala que, de acuerdo a variables transversales de estimación de monto de pensión para países de la OCDE, Chile, junto con España y Australia muestran una sustantiva disminución del monto de sus pensiones respecto de los otros países de la OCDE. Por su parte, si se aplican los parámetros de los otros países al modelo chileno, estos montos aumentan significativamente en algunos países, especialmente Reino Unido, Países Bajos, Noruega, España y Canadá. 
El impacto combinado sobre las pensiones de las mujeres en relación con las de los hombres de los factores vinculados al mercado laboral, por un lado, de los factores vinculados al diseño del sistema de pensiones de capitalización individual, por otro lado, se reflejan claramente en las cifras que publica periódicamente la Superintendencia de Pensiones. Los ahorros previsionales acumulados de las mujeres durante su vida laboral en las AFP equivalen a menos del $50 \%$ de lo reunido por los hombres en el sistema. En promedio, cuando una mujer se jubila a los 60 años, su ahorro llega a 12,5 millones de pesos, el mismo monto que un cotizante hombre suma a sus 49 años. Para cuando un hombre se jubila, a los 65 años, su saldo asciende a los 23 millones de pesos ${ }^{6}$.

El cuadro siguiente resulta de una evidencia clara respecto de la desigual condición de la mujer al momento de su jubilación. A junio de 2018, entre los nuevos pensionados por vejez, entre hombre y mujer existe una brecha de saldo acumulado promedio de $-62,2 \%$ en desmedro de la población femenina, es decir, la población femenina se enfrenta con inferiores montos en su cuenta de capitalización individual para hacer frente a su vejez.

Cuadro 8. Saldo Promedio Nuevos Pensionados de Vejez. en U.F., según sexo julio 2017-junio 2018

\begin{tabular}{c|c}
\hline Sexo del causante & $\begin{array}{c}\text { Saldo promedio por } \\
\text { cotizaciones obligatorias } \\
\text { (UF) }\end{array}$ \\
\hline Hombre & $1.679,57$ \\
\hline Mujer & 634,86 \\
\hline $\begin{array}{c}\text { Brecha de saldos } \\
\text { promedio acumulados }\end{array}$ & $-62,2 \%$ \\
\hline
\end{tabular}

Fuente: Informe de género sobre el sistema de pensiones y seguro de cesantía, Superintendencia de pensiones, septiembre 2018b.

Por su parte y respecto de las tasas de reemplazo, ya a mitad de la década del noventa y según lo indicado por Arenas de Mesa y Gana Cornejo (2001 y 2003); Bertranou y Arenas de Mesa (2003); Pautassi (2002); Pautassi et al. (2011), las estimaciones realizadas indicaban niveles de beneficios muy bajos, es decir, menores tasas de reemplazo respecto de las expectativas de un número importante de asegurados en el sistema de AFP, especialmente de las mujeres. La tasa de reemplazo femenina fluctuaba en ese entonces entre $52 \%$ y $57 \%$ versus un $81 \%$ y $86 \%$

6 http://www.afp-ag.cl/blog/?p=1069. Revisado el 09/05/2019. 
de la masculina. Más de un $50 \%$ de los pensionados obtendría solo un beneficio equivalente al $40 \%$ o inferior a sus últimas rentas. Un $65 \%$ de las mujeres y un $33 \%$ de los hombres tendrían tasas de reemplazo de $40 \%$ o inferiores. La pensión promedio de la mujer retirada a los 60 años era el $60 \%$ de la del hombre y un $87 \%$ si se retiraba a los 65 años.

Las estimaciones realizadas en la década del 90 resultaron en su generalidad muy certeras, ya que, a partir del año 2011, cuando comienzan a expresarse estadísticamente los nuevos jubilados con el sistema de pensión de capitalización individual se hace evidente la baja tasa de reemplazo, expresado en los bajos montos de pensiones, principalmente y de manera dramática para las mujeres que comenzaban su retiro laboral. Desde esa fecha, la expresión cuantitativa se hace sistemática e incremental respecto de la población jubilada y se constata fehacientemente que la población femenina es el actor más perdedor en este nuevo diseño previsional, corroborando la interdependencia de las variables socio laborales, socioculturales y económicas que sitúan a la mujer en un mercado laboral regido aun por valores, principios y paradigmas de tipo patriarcal, jerárquico, segregador y regresivo.

Todo ello se expresa en las brechas de montos de pensiones recibidas por las mujeres en relación a la población masculina. Las brechas son evidentes aun con la incorporación del Aporte Previsional Solidario, elemento incorporado en la reforma previsional del año 2008 que crea el Pilar Solidario, tal como lo expresa gráficamente la siguiente imagen.

Gráfico 5. Sistema de capitalización individual, montos promedio pensión por beneficiarios de APS y brechas de género. Junio 2018

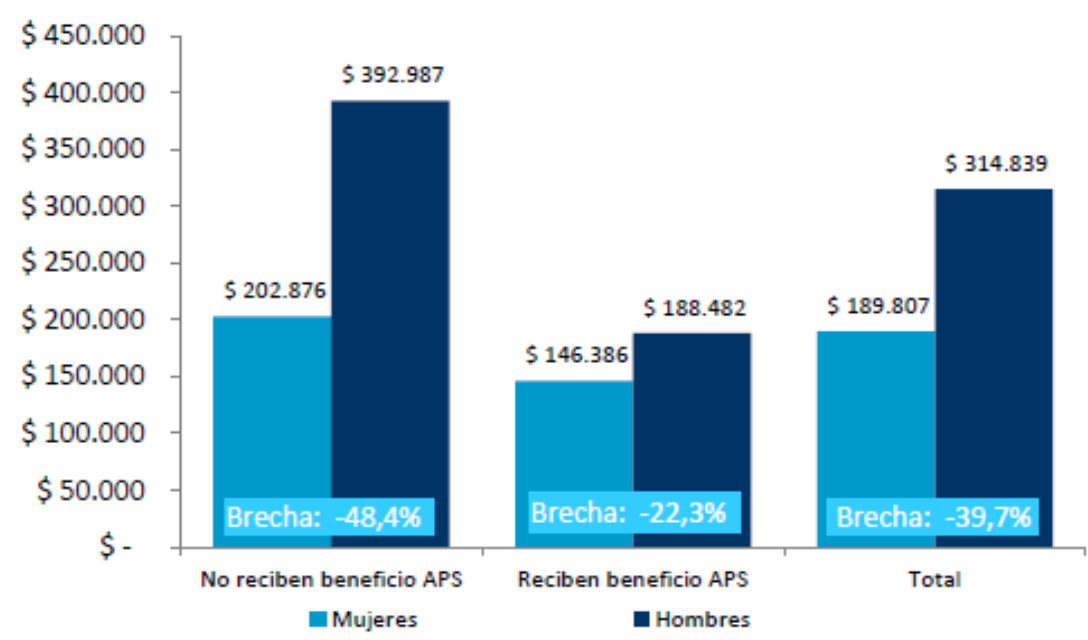

Fuente: Informe de género sobre el sistema de pensiones y seguro de cesantía, Superintendencia de pensiones, septiembre 2018b. 
Como se puede apreciar en el gráfico anterior, la mayor brecha de montos de pensiones entre hombres y mujeres se expresa en las jubilaciones que no reciben beneficios de Aporte Previsional Solidario, monto entregado por el Estado para cubrir las lagunas previsionales de quienes, si cotizaron, pero que sus ahorros no fueron suficientes para alcanzar el monto mínimo garantizado. Así, la brecha entre hombres y mujeres se atenúa entre quienes sí recibieron este APS. Lo que indica que, el Estado en esta modalidad contributiva es un actor central en suavizar las brechas que genera el sistema contributivo, y que éste, a su vez, no asegura mínimos a todos quienes participan del sistema y cotizan, ya que éste se sustenta, finalmente, en la trayectoria laboral y el "esfuerzo individual" de cada cotizante para alcanzar montos mayores de ahorro, escenario en el que la mujer ocupa el lugar más incierto, inestable y precario.

A su vez la brecha de género tampoco escapa a la modalidad de pensión a las que mayormente se acogen los nuevos jubilados y jubiladas. Al respecto y de acuerdo a lo indicado en el gráfico 5, tanto las pensiones modalidad retiro programado, donde se concentran el mayor número de jubilados y la pensión modalidad renta vitalicia, donde se acogen los cotizantes que han logrado un mayor saldo de ahorro individual, expresan brechas significativas. Lo anterior demuestra que, en el caso de las mujeres acogidas a renta vitalicia, con una mejor trayectoria laboral y, por tanto, de ahorro individual, también presentan brechas respecto de los hombres con un no despreciable -26,9\% en relación al monto percibido por los varones en esta modalidad. La modalidad retiro programado, por su parte, resulta la expresión más cruda de la desigual condición estructural a la que se enfrenta la mujer trabajadora al momento de su retiro laboral, con una brecha de un-55,5\% del promedio del monto de pensión percibido por los hombres.

Gráfico 6. Sistema de capitalización individual, monto promedio de pensión autofinanciada, brechas de género por tipo de pensión, junio 2018.

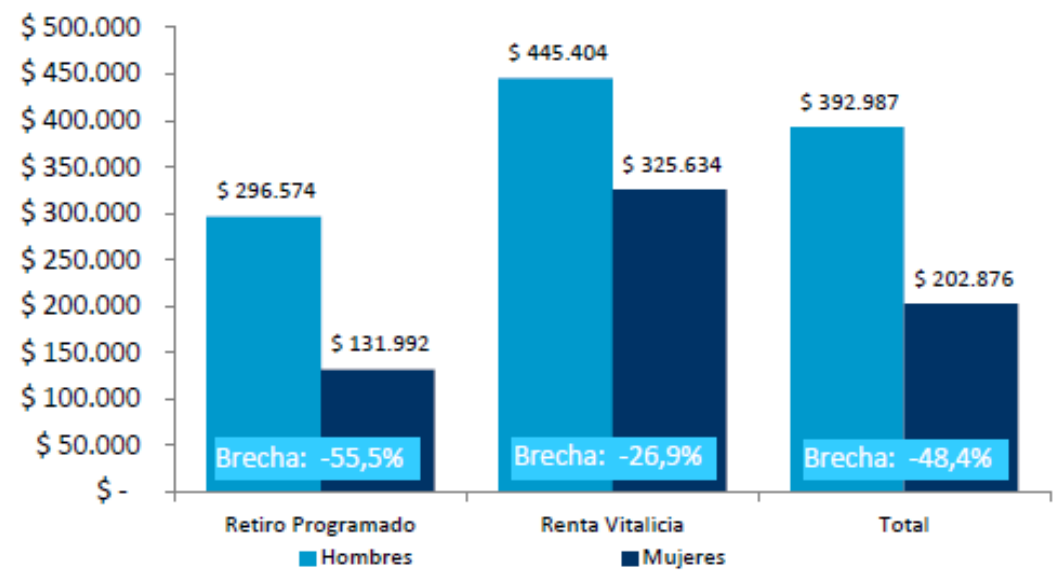

Fuente: Informe de género sobre el sistema de pensiones y seguro de cesantía, Superintendencia de pensiones, septiembre 2018 b. 
Finalmente, el cuadro 9 muestra el aporte estatal para el pilar solidario en los componentes contributivo y no contributivo del sistema de pensiones de Chile. Al año 2018 el estado gasto carca de dos mil millones de dólares en ambos componentes, beneficiando en términos globales a más de un millón 500 mil pensionados.

Lo que evidencia la relevancia y necesidad de la presencia del estado frente a un sistema de pensiones, basado en ahorro individual y de administración privada, que no logra configurar cubrir por sí mismo un sistema de seguridad social eficiente, sostenible ni garante de pensiones suficientes, mediante un beneficio definido, especialmente a la población femenina, cuyos resultados y saldos, ya analizados, corren en importante desventaja para sus años de retiro laboral.

Cuadro 9. Aporte del estado, sistema previsional componente solidario PBS y APS año 2018

\begin{tabular}{|c|c|c|}
\hline Tipo de pensión & Millones de pesos & Millones de dólares \\
\hline Pensión Básica Solidaria & $\$ 800.572$ & US\$ 1.151 \\
\hline Aporte Previsional Solidario & $\$ 588.761$ & US\$ 846 \\
\hline Total Pilar Solidario & $\$ 1.393 .333$ & US\$ 1.997 \\
\hline $\mathrm{N}^{\circ}$ de Pensionados Beneficiados & \multicolumn{2}{|c|}{1.507 .592} \\
\hline
\end{tabular}

Fuente: Gálvez \& Kremerman, 2019.

III. Ámbitos de intervención para restituir un derecho y un reconocimiento social y jurídico a la mujer en el mercado productivo y laboral y en su retiro laboral

Los ámbitos de intervención para hacer frente a las desigualdades de género en el actual sistema de pensiones, pasan, entre otros aspectos, por realizar un abordaje multivariable y multisectorial en este sector, ya que los fenómenos de la vejez, del trabajo y del retiro digno implica la coordinación de amplios sectores del quehacer público, ya que se trata de una macro política pública, donde la acción parcelada a nivel de gestión institucional y de los recursos públicos no alcanza un real asidero en las transformaciones que se requieren.

Si bien el mercado laboral acentúa la precariedad laboral y la baja densidad de cotización femenina, la estructura y diseño del modelo de AFP representa el basamento de un sistema cuyo principal objetivo fue la acumulación de activos financieros a escala nacional, en base a los ahorros previsionales aportados por cada trabajador y trabajadora cada mes, para capitalizar el nuevo modelo de desarrollo chileno, cuyas principales medidas estructurales fundacionales fueron 
cristalizadas en el Consenso de Washington. Es así que el éxito de dicho modelo previsional implementado fue en lo concreto el aumento de capital financiero acumulado en base a la especulación financiera en el mercado bursátil tanto nacional como internacional, lo que trajo de la mano, una precarización y devaluación del valor del trabajo o también llamado valor hora - trabajador/a. Lo anterior, pues una de las variables que toma fuerza en el mercado de valores de la economía especulativa financiera, que eleva los bonos accionistas de las empresas, es precisamente el menor costo de contratación de mano de obra, como parte de los costos productivos generales, lo que implica que, en la medida que el valor hora persona es más bajo en una empresa, esta demuestra ser más eficiente en su cadena de valor productivo, lo que redunda en un mayor margen de ganancias, a su vez estimula el aumento de las posiciones en la venta de acciones y la especulación financiera. Lo anterior afecta a todo trabajador que cotiza en AFPs, pero afecta de manera exponencial a la mujer, cuando recibe un $30 \%$ menos de sueldo que un hombre, y cuando dicho sistema ha generado y consolidado una matriz productiva de bajo valor agregado, orientada al extractivismo exportador, el sector terciario de la economía con fuerte énfasis en el comercio y los servicios y por lo tanto, necesitado de mano de obra de baja calificación, de alta estacionalidad y que permite y estimula su precarización, donde nuevamente la mujer se ubica en clara desventaja.

Por otra parte, el actual sistema de pensiones se fundamenta en una serie de principios que fomentan y estimulan un comportamiento de los sujetos sociales en la competencia, la eficiencia, el rendimiento y la individualidad. Concibe la seguridad social no como un derecho social universal, sino como un dispositivo para la vejez al cual se puede acceder de manera diferida y parcelada o sistemática, según la trayectoria y desempeño laboral individual de cada sujeto. Así, individualiza la responsabilidad de la trayectoria laboral y previsional del o la trabajadora, apelando a una concepción distorsionada del concepto de meritocracia, en la medida que el esfuerzo individual tiene como saldo un mejor monto de ahorro, pero castiga cuando ese esfuerzo individual no es suficiente y la trayectoria laboral individual no se ajusta al modelo o tipo ideal proyectado en su diseño original el sistema de AFP. Por lo tanto, el éxito o fracaso del financiamiento adquirido en los años de actividad laboral recae en el desempeño, adecuación o no al mercado laboral y la propia posibilidad de construir un futuro más o menos favorable para la etapa de jubilación. Acentuando aún más la frustración en esta etapa de la vida, dado tanto por el bajo monto de pensión percibido como por la adjudicación de una responsabilidad personal en el resultado de dicha situación. Este sentimiento se acentúa aún más en la mujer, al ir perdiendo en la vejez, redes de apoyo social, contención psico emocional y el debilitamiento de capacidades productivas que se traducen en una menor autonomía personal y económica.

Así, el sistema de capitalización individual, está basado en muchos supuestos que, de acuerdo a la evidencia estadística que ha arrojado el sistema de pensiones con ya casi cuarenta años de vigencia, constata que esos supuestos 
no se cumplieron, tales como una densidad de cotizaciones sobre los veinte años para la mujer y un mercado laboral de pleno empleo. La capitalización individual se basó en que su funcionamiento sería optimo en la medida que todas las ocupaciones y ramas laborales recibirían salarios adecuados y continuos que les permitirían ahorrar para su vejez, escenario que sería condición y efecto a la vez en el mercado laboral del nuevo modelo previsional, situación que no se ajusta a la realidad del país.

El anterior estado de cosas que definen el operar y el impacto del sistema de AFPs en lo financiero (como dispositivo para generar utilidades de manera agregada) como en lo social (entendido como mecanismo o dispositivo generador de pensiones) como un sistema marcadamente desigual y pauperizante de la condición social y del sujeto mujer en su condición de jubilada, solo es factible de modificar en tanto ocurran, de manera gradual pero con perspectiva de urgencia social, diversas transformaciones y medidas de tipo estructural que tiene que ver con una nueva mirada cultural de las identidades, los roles y relaciones de género en sociedad y como en ello se expresan las desigualdades de poderes, valoraciones sociales y funcionales de la condición femenina y masculina. Asimismo, las mujeres han escuchado muchas veces las causas de la pobre jubilación que reciben en Chile; tales como la alta inactividad laboral, desempleo, bajos salarios, empleos informales, menor edad de retiro, mayor esperanza de vida, entre otras, pero se soslaya que estas causas no son por voluntad propia de las mujeres, sino que obedecen a representaciones sociales y culturales que se materializan en los modos de ser y hacer en las instituciones y en términos generales a nivel estructural de los poderes facticos. En lo cotidiano se refleja en identidades y funciones sociales correspondiente a roles de género impuestos histórica y socialmente y que determinan distintos tratos, distintos enmarcados normativos en los cuales se aplican y tienen asidero los derechos, sus alcances, posibilidades y límites de manera diferenciada.

Se hace necesario entonces un nuevo pacto social, donde las tareas de crianza, cuidados y reproducción social sean compartidas, donde las desigualdades que actualmente experimentan las mujeres en el trabajo y por ende en el resultado de su previsión social vayan siendo menos evidentes. Las reformas parciales que se han aplicado en el sistema previsional en Chile (Reforma Previsional de 2008 que integra el Pilar Solidario y el APS por ejemplo), continúan viendo a la mujer como sujeto merecedor de asistencia social. Lo que se requiere es la construcción de una nueva mirada. Que estas sean vistas como sujetos de derecho frente al sistema previsional.

Las aún existentes y arraigadas pre concepciones que sitúan a la mujer de manera diferenciada en la división sexual del trabajo en tareas de cuidado, crianza y labores domésticas. Que asume una concepción de la educación, de la calificación y el entrenamiento laboral de corte sexista, la cual tiene como basamento el razonamiento de raíz patriarcal y vertical que, por una parte, ve a la mujer como un sujeto circunscrito inevitablemente por su condición biológica de 
reproductora y a la cual se la unidimensionaliza como sujeto a partir de estos rasgos y características biológicas. Negando o limitando, con ello, el valor a sus otras dimensiones tales como su dimensión política y con ello su condición de sujeto o agente portador de cambio social; productiva; legal; económica; creativa; entre otras. Al respecto, y producto de esta unidimensionalización de la mujer es que esta, en la rueda de la historia ha sido la eterna alumna desventajada o rezagada llegando, por tanto, a las conquistas sociales, políticas, jurídicas, economías etc., décadas más tarde y bajo costos humanos mayores que su par masculino. En esto, su derecho a la seguridad social también corre en carrera diferida.

Por otra parte, los drásticos cambios en la composición familiar en Chile, requieren de una lectura actualizada y comprehensiva de los nuevos factores que definen su estructura, rompiendo de manera acentuada con los paradigmas tradicionales de la familia conservadora de tipo biparental, nuclear y heterosexual. Ello requiere de una comprensión profunda de factores sociológicos, psicosociales, culturales, antropológicos, económicos y políticos que han penetrado en las subjetividades, valoraciones y nuevos sentidos comunes respecto del valor y sentido de hacer familia, ampliando el rango de posibilidades de esta. Asimismo, nuevos fenómenos como la baja natalidad, una mayor esperanza de vida, una concepción más amplia de la maternidad y una mayor diversidad de opciones y proyectos vitales, hacen de la mujer un sujeto social más complejo y dinámico, restando centralidad o viviendo en una expectativa nueva la maternidad y la crianza. Incluso apostando por ella desde la ausencia del modelo paterno. Asimismo, las mayores coberturas educacionales, especialmente en los últimos veinte años, permiten abrigar nuevas y mejores expectativas de desarrollo laboral y profesional en las mujeres, haciéndolas más autónomas y más pro activas en este ámbito.

Todos estos factores, han reconfigurado el rol, presencia y expectativa de la mujer en una sociedad que cada vez se aleja más de las pautas de relaciones sociales del siglo XX, ancladas en instituciones tradicionales que, de cierta forma constreñían su identidad y posibilidades vitales, que hoy en día ve más ampliadas y que, pese a los cambios culturales, especialmente en la composición de la familia y la presencia de la mujer en diversos ámbitos del quehacer social, las instituciones y estructuras que definen y diseñan las políticas públicas y los modelos de desarrollo a nivel nacional, aún no integran esta nueva realidad al diseño y propósitos de las políticas públicas o las integran de manera poco acentuada y desconectadas con el sistema social e institucional nacional en su conjunto, sin lograr entender que la nueva realidad evidenciada en la praxis de las personas, de vastos sectores de la población y de la evidencia internacional, son un engranaje más de un sistema sociocultural que en su conjunto forza por las transformaciones.

Una lectura parcelada, tardía, poco conectada con las necesidades de desarrollo social y económico que requiere el país, por parte de quienes están a la cabeza de las instituciones y las decisiones, seguirá decodificando la seguridad 
social no como un derecho, ni reconociendo a la mujer como un sujeto social, ni en su aporte a la sociedad, ni en sus necesidades vitales en la etapa de su vejez.

Muy de la mano de la dimensión cultural, en el ámbito de la educación, significa construir en este sector una nueva cultura de género, de derechos y deberes, de corresponsabilidad y de colaboración, implica un destierro de prejuicios y valoraciones del sujeto mujer y hombre en función de la anquilosada relación binaria de dominación y superposición de lo masculino sobre lo femenino. En este sentido implica la deconstrucción de las cosmovisiones sociales y culturales que ubican a la mujer y todo lo referido a lo femenino en relación y sujeto a cualidades y capacidades de "menor espesor y densidad" respecto a su necesidad e impacto para la construcción de sociedades más efectivas, eficientes y equitativas. Implica además el desafío de la reconstrucción de una educación en un nuevo paradigma social y filosófico, que ponga en el centro las capacidades de agencia de lo femenino en su real potencial transformador.

En el mercado del trabajo, implican la creación de leyes y normas que efectivamente vayan en la línea de equiparar para hombres y mujeres labores y obligaciones tanto laborales como de crianza y cuidados, tal como lo han alcanzado, en distintos grados, pero de manera efectiva países como Suecia ${ }^{7}$, Noruega ${ }^{8}$, Dinamarca, entre otros. Implica también una reforma a la ley de posnatal, la cual sigue endosando a la mujer la mayor responsabilidad en el cuidado del hijo en función de un mayor acercamiento a la conciliación trabajo-familia.

Implica, además, una revalorización del trabajo como una actividad eminentemente social y productiva, donde se construye de manera colaborativa y colectivamente un desarrollo y bienestar material para las personas y donde se desarrollan (en conjunto con la educación formal y no formal) los capitales cívicos de la población. Implica un nuevo concepto y planificación de la idea de productividad laboral, que conjugue modelo de desarrollo, una red articulada e interconectada de formación y capacitación para el trabajo con perfiles productivos y polos de desarrollo regional/local y nacional, que implique una formación para el trabajo no sexista, sino colaborativo, articulado en nodos formativos poli productivos y polifuncionales como círculos virtuosos y complementarios que abarquen una red densa de los oficios y necesidades de capacitación y organización de la empresa en función de lo polos de desarrollo existentes en cada territorio. Acompañado de medidas antidiscriminación y de integración de género claras, estrictas en su cumplimiento y que implique como requisito base la igualdad salarial y de estabilidad laboral para hombres y mujeres.

\footnotetext{
7 Rangecroft (2016). El Plan de Suecia para que los hombres tomen mas licencia cuando tengan hijos. 7 enero 2016. Revisado 07 - 06 - 2020. En: https://www.bbc.com/mundo/noticias/2016/01/160106_cultura_suecia_licencia_paternidad_wbm

8 Chemin, A. (2011) Ley de licencia de paternidad ayuda a crear hogares más iguales. 19 - 06 - 2011. Revisado 07 - 06 2020. En: https://www.theguardian.com/money/2011/jul/19/norway-dads-peternity-leave-chemin
} 


\section{Conclusiones}

Tal como se han conjugado las variables antes descritas, la pobreza en Chile tiene rostro de mujer, y tiene rostro de mujer mayor. El aumento de la participación laboral femenina será un aporte a la disminución de la pobreza, teniendo en cuenta que un 39,5\% de los hogares en Chile tiene una jefatura femenina (CASEN 2017). Es por ello que la creación de políticas públicas para equiparar las desigualdades debe ir enfocadas a incentivar la participación de las mujeres en la fuerza laboral, más allá de medidas inmediatistas, de corte paternalistas y transitorias como las conocidas transferencias monetarias en base a bonos; se hace necesario un compromiso de parte de todos los actores de la sociedad, donde exista una obligación de realizar una distribución más equitativa de los roles de género, tanto en el ámbito privado como en el público.

La desigualdad de género en Chile es evidente y los avances para su destierro van ocurriendo de manera muy lenta, es una batalla principalmente de tipo cultural y política.

La concepción de seguridad social establecida bajo el decreto 3.500 en 1981, en base a un ahorro forzado a través de cuentas individuales, establece principios diametralmente antagónicos a los que dieron origen a la seguridad social tanto en Chile como en muchos países de Europa y América Latina en la primera mitad del siglo XX, la cual se forjo como un proceso socio político de largo aliento en la construcción de una política de seguridad social donde primo la activa incidencia y participación de los distintos actores socio políticos y del mundo del trabajo, en la búsqueda de mejores condiciones para masas de trabajadores y trabajadoras que se integraban al desarrollo y construcción de los estados a través de los procesos de la industrialización y urbanización.

La concepción de una corresponsabilidad en la seguridad social, sobre la base del ejercicio de la solidaridad en la construcción colectiva de un armazón institucional y del aporte a los ahorros necesarios para dar respuesta a los períodos de retiro laboral, característicos y propios de los estados naciones del siglo XX, asumen la retirada de manera drástica en Chile, tomando forma una concepción de la seguridad social en la vejez, de cuyo resultado su responsabilidad es asumida como un objetivo personal e individual. Es así como el saldo de cada cuenta de ahorro es el resultado del desempeño personal de cada individuo en el mercado del trabajo, y los costos del saldo negativo, al final del camino, sean por una baja densidad de cotizaciones, por bajos montos de ahorro mensual o, por las pérdidas de quienes asumen, (las AFPs), la responsabilidad de generar la financiarización del sistema en cada cuenta, en los mercados especulativos, recaen inexorablemente en el trabajador. 
Dicha dinámica, si bien castiga y golpea en términos generales tanto a hombres como mujeres, por las características propias del diseño del modelo; de ahorro individual, de participación en la cotización y ahorro solo de parte del trabajador (independientemente del APV), de tablas de mortalidad diferenciadas para las mujeres, con edad de retiro diferenciada de manera desventajosa para las mujeres y donde estos ahorros son rentabilizados en los mercados especulativos nacionales e internacionales, donde la volatilidad es lo que los caracteriza, Los resultados y saldos generales de toda la operatividad del sistema recae más desventajosamente en la mujer.

El diseño del modelo de pensiones, unido al mercado laboral y la estructura normativa que lo regula, más una matriz productiva caracterizada por el escaso componente productivo junto a un alto desarrollo del sector terciario, principalmente de los servicios y el área financiera, devienen en un engranaje que trenza un círculo virtuoso (vicioso) proclive a configurar una economía fuertemente agregada, de baja competencia, de escaso valor agregado, de fuerte aliento al mercado financiero, donde no requiere de un mercado laboral de alta calificación y donde, por antonomasia, se estimula un ahorro de los costos operacionales que tiene como saldo una estructura salarial muy deficitaria. En este escenario, la mujer trabajadora se enfrenta a condiciones adversas, sumado a una división social y sexual del trabajo, estimulado y configurado por una cultura conservadora, machista y segregadora, donde aún se prefiere que, por una parte, sea la mujer la que debe asumir en su generalidad el cuidado y crianza de hijos y personas $\sin$ autonomía (generalmente mayores), y donde, por otra parte, se asume que es el hombre trabajador el jefe de familia y el principal proveedor de ésta.

Asimismo, sumado a lo anterior, las pautas culturales de socialización y conformación de las identidades de género, son fuertemente permeadas a las políticas educacionales con una visión sesgada en torno a una educación, socialización temprana y formación profesional sexista. Las estructuras educacionales y el estímulo temprano principalmente en el hogar y en la educación pre básica, van en la línea de estimular en niños y niñas áreas del quehacer y del saber diferenciadas sexualmente, donde las que tiene que ver con la asistencia y atención de los otros van dirigidas preferentemente a las mujeres y las que tienen que ver con el manejo del poder, de la resolución de problemas y de la administración y dirección van enfocadas a los varones. Todas estas áreas que, en los escenarios de la oferta y demanda del trabajo, igualmente son valorados culturalmente y salarialmente de manera diferenciada por género, siendo las mujeres quienes en su mayoría asuman actividades laborales de baja densidad, con menor responsabilidad gerencial y de administración y quienes si deciden romper dichas barreras culturales, asumen un camino de mayor complejidad, rezago y discriminación en su inserción y trayectoria laboral. 
Asimismo, Chile es un país con una baja participación ciudadana, y este fenómeno que se expresa socialmente es de raíz cultural, política e ideológica. Lo cual hace que actualmente y pese al llamado estallido social, surgido en octubre del año 2019 la presión, supervisión y control por parte de la sociedad civil hacia el gobierno o los actores políticos sea nula o no rinden efectos en el estado de cosas a nivel político, por no existir instrumentos de incidencia de la sociedad civil efectivos y que encaucen de manera concreta ciertas expresiones de control. Por lo tanto, las medidas que se tomen en cuanto a políticas públicas o reformas normativas o institucionales en cuanto a disminuir ciertas brechas de género respecto de la seguridad social, no tendrán a todos los actores sentados a la mesa. Este tipo de política requiere de la presencia de todos los actores sociales, mediante un diálogo social, político, económico y cultural amplio y generoso y con perspectiva de largo plazo.

Se requiere, por tanto, replantear un sistema que ponga el foco en la generación de un efectivo sistema previsional para los y las trabajadoras y que ponga énfasis en un equiparamiento de los montos de pensiones entre hombres y mujeres, bajo las lógicas y fundamentos de las declaraciones y principios internacionales en torno a la previsión social que en algún momento orientó e inspiró las políticas de seguridad social en Chile y que han sido comentadas. Entre ellas, la solidaridad intergeneracional e intrageneracional, de reparto, tripartita, la universalidad de su acceso, la suficiencia en su monto, y le agregaríamos a los tiempos e imperativos éticos y sociales que corren y demandan; con una acentuada mirada de género, enfocada en las necesidades de la mujer como sujeto y actor social de derecho, como un derecho a cubrir de manera ineludible e inalienable.

Así y dados los antecedentes numéricos y concretos del saldo tan desigual por género en la operatividad del modelo de pensiones a casi cuarenta años de su vigencia en Chile, se requiere urgentemente diseñar un sistema de seguridad social sobre la base de las necesidades que la población requiere y subsanar las desigualdades de un modelo de desarrollo concentrador de las riquezas. Se requiere un modelo de previsión social ajustado a los contextos y cambios socio culturales del siglo XXI y el conjunto de expectativas que ello entraña en una población más demandante de participación e injerencia en lo social. Lo anterior requiere una toma de distancia respecto de los principios e imperativos macroeconómicos y de un excesivo tecnicismo, inspirados en un dogmatismo radical base del modelo neoliberal. En el cual se sustenta el modelo de pensión de ahorro individual, el cual requiere como anclaje y base una nueva concepción de desarrollo país. Este giro, gravita igualmente, en torno a un cambio de concepción de la seguridad social, o más bien en la senda de recuperar el sentido originario de la seguridad social, que dio forma jurídica, sustento financiero, legitimidad social 
y ética política a los sistemas de seguridad social hasta antes del año 1980 y ello debe incluir un principio de restitución de derechos y de inversión o rentabilidad social. Concepto este que adquiere un alcance y una solidez en su operatoria y posteriores impactos que pasan a convertirse en importantes vértices tanto de la estabilidad social, de un buen vivir, sobre la base de la garantía de mínimos éticos asegurados. Por otra parte, representa un contrapeso y amortiguador frente a crisis económicas recurrentes, ya que permite fortalecer y dinamizar la economía interna, evitando la exposición a los deterioros, vaivenes y volatilidad de componentes del mercado internacional, factores componentes de las economías tan abiertas y desreguladas como es la economía chilena.

Ello significa, finalmente como prerrequisito, cambios culturales profundos y como procesos sostenibles en el tiempo, que decanten en transformaciones de valoración social y cultural, en primera instancia y de cambios institucionales, en segunda instancia que materialicen un tipo de relación sociedad/instituciones democráticas que permita allanar y distribuir más equitativamente los poderes entre los actores y en ellas la mujer, como actor imprescindible para la reproducción social, la reproducción de la fuerza de trabajo, la reproducción del capital social y de la cohesión social, tan necesaria e imprescindible en el desarrollo de las sociedades. Labor que, bajo estos parámetros y criterios de puesta en valor deben ser reconocidos como derechos a su participación y contribuidos remunerativamente, tanto en tiempos de vigencia y actividad laboral como en el período de retiro y descanso. 


\section{Referencias bibliográficas}

Arenas de Mesa, A., \& Gana Cornejo, P. (2003). Protección social, pensiones y género en Chile. En F. Bertranou, \& A. Arenas de Mesa (eds.), Protección social, pensiones y género en Argentina, Brasil y Chile. Santiago de Chile: Oficina Internacional del Trabajo.

Arenas de Mesa, A., \& Gana Cornejo, P. (2001). Reforma a los sistemas de pensiones y los desafíos de la dimensión de género. Población y Desarrollo, № 18 (LC/L.1614-P). Santiago: Comisión Económica para América Latina y el Caribe (CEPAL).

Banco Mundial. (2019). Tasa de participación en la fuerza laboral, mujeres (\% de la población femenina entre 15-64 años) (estimación modelado OIT). Recuperado de https://datos.bancomundial.org/indicador/SL.TLF.ACTI.FE.ZS.

Banco Mundial (2019a). Desempleo, mujeres (\% de la población activa femenina) (estimación modelado OIT). Recuperado de https://datos.bancomundial. org/ indicator/SL.UEM.TOTL.FE.ZS.

Barriga, F., Duran G., Sáez, B., \& Sato, A. (2020). No es amor, es trabajo no pagado: Un análisis de trabajo de las mujeres en el Chile actual. Estudios de la Fundación SOL. Recuperado de http://www.fundacionsol.cl/wp-content/ uploads/2020/03/No-es-amor-es-trabajo-no-pagado-2020.pdf.

Bertranou, F., \& Arenas de Mesa, A. (Eds.) (2003). Protección social, pensiones y género en Argentina, Brasil y Chile. Santiago de Chile: Organización Internacional del Trabajo (OIT).

Comisión Económica para América Latina (CEPAL). (2002). Ciudadanía y Protección Social en Pensiones con Equidad de Género. Recuperado de https://www. cepal.org/mujer/noticias/noticias/1/11151/orgulloso.pdf.

Comisión Económica para América Latina (CEPAL). (2010). La dimensión de género en la reforma previsional chilena (Ley No 20.255 de reforma de pensiones). Recuperado de https://www.cepal.org/es/publicaciones/5823-la-dimensiongenero-la-reforma-previsional-chilena-ley-20255-reforma-pensiones.

CIEDESS (2019). Situación de la mujer en países de la OCDE: Simulaciones y comparativo de montos de pensiones según cada país. Nota técnica No. 45. Gerencia de estudios. Recuperado de https://www.ciedess.cl/601/ articles-3854_archivo_01.pdf. 
Chemin, A. (19 de julio de 2011). Ley de licencia de paternidad ayuda a crear hogares más iguales. The Guardian. Recuperado de https://www.theguardian. com/money/2011/jul/19/norway-dads-peternity-leave-chemin.

Encuesta CASEN (2017). Observatorio Social, Gobierno de Chile. Recuperado de http://observatorio.ministeriodesarrollosocial.gob.cl/casenmultidimensional/casen/casen_2017.php.

Fundación Sol (2014). Desde un Sistema de AFP hacia un Sistema de Pensiones basado en los principios de la Seguridad Social. Diagnóstico desde el punto de vista del Sistema de Reparto. Recuperado de http://www.fundacionsol. $\mathrm{cl} /$ descargables/desde-sistema-afp-hacia-sistema-pensiones-basado-losprincipios-la-seguridad-social/.

Gálvez, R., \& Kremerman, M. (2020). Pensiones bajo el mínimo. Los montos de las pensiones que paga el sistema de capitalización individual en Chile: Documento de trabajo 2020. Recuperado de http://www.fundacionsol.cl/ wp-content/uploads/2020/06/PBM2020-1.pdf.

Gálvez, R., \& Kremerman, M. (2019). Pensiones por la fuerza: Resultados del sistema de pensiones de las Fuerzas Armadas y de Orden. Recuperado de http://www.fundacionsol.cl/wp-content/uploads/2019/09/PEV-1.pdf.

Gobierno de Chile (2019). Encuesta Casen Mujer revela situación socioeconómica y brechas de las mujeres en Chile. Recuperado de https://www.gob.cl/ noticias/encuesta-casen-mujer-revela-situacion-socioeconomica-y-brechasde-las-mujeres-en-chile/.

González, A. (2017). La desigualdad previsional de género en Chile. (Tesis de magister). Universidad de Chile. Santiago, Chile. Recuperado de http://repositorio.uchile.cl/bitstream/handle/2250/151571/La-desigualdadprevisional-de-g\%C3\%A9nero-en-Chile. pdf?sequence=1\&isAllowed=y.

Granados, O. (10 de marzo de 2019). La mujer latina sigue a la cola del mercado laboral. El País. Recuperado de https://elpais.com/economia/2019/03/07/ actualidad/1551949955_972742.html.

Instituto Nacional de Estadísticas (2016). Menos del 50\% de las Mujeres Participó en la Fuerza Laboral Durante el 2015. Recuperado de http://webanterior. ine.cl/prensa/detalle-prensa/2016/05/30/menos-del-50-de-las-mujeresparticip\%C3\%B3-en-la-fuerza-laboral-durante-2015. 
Instituto Nacional de Estadística (2018). Encuesta Suplementaria de Ingresos. Recuperado de https://www.ine.cl/estadisticas/sociales/ingresos-y-gastos/ encuesta-suplementaria-de-ingresos.

Instituto Nacional de Estadística. (2020a). Boletín estadístico: Empleo trimestral. Edición No. 259. Recuperado de https://www.ine.cl/docs/default-source/ ocupacion-y-desocupacion/boletines/2020/pa\%C3\%ADs/bolet\%C3\%ADnempleo-nacional-trimestre-m\%C3\%B3vil-febrero-marzo-abril-2020.pdf.

Instituto Nacional de Estadísticas (2020b). Boletín estadístico: Empleo trimestral. Edición No. 255. Recuperado de https://www.ine.cl/docs/default-source/ ocupacion-y-desocupacion/boletines/2019/pais/boletin-empleo-nacionaltrimestre-movil-octubre-noviembre-diciembre-2019.pdf.

Maldonado, C., \& Palma, A. (2013). La construcción de pactos y consensos en materia de política social. El caso de la reforma previsional en Chile (20052008). Políticas Sociales N¹83, Santiago de Chile: CEPAL.

Organización Internacional del Trabajo. (2017). El mercado laboral en Chile: Una mirada de mediano plazo. Recuperado de https://www.ilo.org/ wcmsp5/groups/public/---americas/---ro-lima/---sro-santiago/documents/ publication/wcms_632360.pdf.

Pautassi, L. (2002). Legislación previsional y equidad de género en América Latina. Mujer y Desarrollo $N^{\circ} 42$. Santiago de Chile: CEPAL. Recuperado de http:// repositorio.cepal.org/bitstream/handle/11362/5898/S0210838_es.pdf;jsess ionid=3F1A91F08D5D7CCA6BB7A16A7F345846? sequence $=1$.

Pautassi, L., Giacometti, C., \& Gherardi, N. (2011), Sistema previsional en Argentina y equidad de género: Situación actual (2003-2010) y perspectivas futuras. Recuperado de http://www.ela.org.ar/a2/objetos/adjunto.cfm?codcontenid $\mathrm{o}=1234 \&$ codcampo=20\&aplicacion $=a p p 187 \& \mathrm{cnl}=87 \& \mathrm{opc}=53$.

Rangecroft, A. (7 de enero de 2016). El Plan de Suecia para que los hombres tomen más licencia cuando tengan hijos. Estocolmo Suecia. BBC News. Recuperado de https://www.bbc.com/mundo/noticias/2016/01/160106 cultura_suecia_licencia_paternidad_wbm.

Superintendencia de pensiones (2018). Reforma previsional: Principales propuestas. Recuperado de http://www.spensiones.cl/portal/ institucional/594/articles-13449_archivo_01.pdf.

Superintendencia de Pensiones, (2018a). Informe de género sobre el sistema de pensiones y seguro de cesantía. Septiembre 2018. Reporte anual. Recuperado 
de https://www.spensiones.cl/portal/institucional/594/articles-13403_ recurso_1.pdf.

Superintendencia de Pensiones (2018b). Informe de género sobre el Sistema de Pensiones y el Seguro de Cesantía. Recuperado de https://www.spensiones. cl/portal/institucional/594/articles-13562_recurso_3.pdf.

Superintendencia de Pensiones (2019). La Superintendencia de pensiones y la igualdad de género. Recuperado de https://www.spensiones.cl/portal/ institucional/594/w3-article-13562.html.

Zilleruelo, H. (2017). Calculo de tasa de reemplazo y las determinantes que la originan (Tesis de magister) Universidad de Chile, Santiago, Chile. Recuperado de http://repositorio.uchile.cl/bitstream/handle/2250/145687/ Zilleruelo\%20Riquelme\%20Horacio.pdf?sequence=4\&isAllowed=y.

Dirección de correspondencia:

Jacqueline Crespo Amigo

Socióloga U. de Chile. Articulo elaborado en el marco de su formación en el Programa de Magister en Políticas Públicas y Procesos Locales Universidad Católica del Maule. Año 2019.

Contacto: jcrespoamigo@gmail.com

Esta obra se encuentra bajo una Licencia de Creative Commons

Reconocimiento-NoComercial-Compartirlgual 4.0 Internacional 